\title{
El análisis molecular y el inmunogénico sugieren la ausencia de las proteínas hidrofílicas de superficie en Leishmania (Viannia) panamensis
}

\author{
Marcel Marín', Yudy Alexandra Aguilar², José Robinson Ramírez³, Omar Triana4, \\ Carlos Enrique Muskus ${ }^{1}$ \\ ${ }_{1}^{1}$ Programa de Estudio y Control de Enfermedades Tropicales (PECET), Facultad de Medicina, Universidad \\ de Antioquia, Medellín, Colombia \\ ${ }^{2}$ Grupo Investigador de Problemas en Enfermedades Infecciosas (GRIPE), Facultad de Medicina, Universidad \\ de Antioquia, Medellín, Colombia \\ ${ }^{3}$ Grupo de Inmunomodulación, Facultad de Medicina, Universidad de Antioquia, Medellín, Colombia \\ ${ }^{4}$ Grupo de Chagas, Instituto de Biología, Universidad de Antioquia, Medellín, Colombia
}

Introducción. Los dos subgéneros en los cuales se divide el género Leishmania: Viannia y Leishmania, presentan diferencias significativas en las manifestaciones clínicas que causan, en su comportamiento de crecimiento en cultivos in vitro, en sus características genéticas y en la expresión de varias proteínas, entre ellas las de la familia hidrofílica de superficie superficie. Objetivo. Caracterizar las proteínas hidrofílicas de superficie en Leishmania (Viannia) panamensis.

Materiales y métodos. Se amplificaron los genes hasp en L. (V.) panamensis usando cebadores específicos para la especie Leishmania (Leishmania) major. Los productos de la amplificación fueron clonados, secuenciados y analizados con herramientas bioinformáticas. Posteriormente, se realizó un análisis serológico por medio de ensayo inmunoabsorbente ligado a enzimas y Western blot para detectar la presencia de anticuerpos específicos contra las proteínas hidrofílicas recombinantes de superficie de $L$. (L.) major en sueros de pacientes con leishmaniasis de zonas endémicas de Colombia.

Resultados. Se encontró una copia de un pseudogen en $L$. (V.) panamensis, el cual presentó una identidad del $60 \%$ con el gen haspa de $L$. (L.) major. Sólo se encontraron anticuerpos contra las proteínas recombinantes de superficie hidrofílicas en sueros de pacientes con leishmaniasis visceral.

Conclusión. Estos resultados sugieren que no existe ninguna copia de un gen funcional hasp en $L$. ( $V$.) panamensis, lo que indica una pérdida de la familia de genes en esta especie de Leishmania perteneciente al subgénero Viannia.

Palabras clave: Leishmania, reacción en cadena de la polimerasa, clonación molecular, datos de secuencia molecular, prueba ELISA, Western blotting.

Molecular and immunological analyses suggest the absence of hydrophilic surface proteins in Leishmania (Viannia) panamensis

Introduction. The genus Leishmania is divided into two subgenera: Leishmania and Viannia. The two subgenera present several important differences such as the pathology they cause in susceptible hosts, their in vitro growth behavior, their genetic characteristics, and the expression pattern of several proteins, including those of the hydrophilic surface protein family.

Objective. To characterize the hydrophilic surface protein family in Leishmania (Viannia) panamensis.

Materials and methods. The hasp genes were amplified in $L$. (V.) panamensis, using specific primers previously designed to amplify this gene in Leishmania (Leishmania) major. The PCR products were cloned, sequenced, and the sequences analyzed using common bioinformatics tools. Secondly, a serological screening was undertaken with an enzyme-linked immunosorbent 
assay and Western blot to detect specific antibodies against the hydrophilic surface recombinant protein from L. (L.) major.

Results. A copy of a pseudogene was amplified in L. (V.) panamensis which was $60 \%$ homologous with the L.(L.) major orthologous gene. Antibodies responded to the hydrophilic surface recombinant proteins only in sera from patients with visceral leishmaniasis [Leishmania (Leishmania) chagasi].

Conclusión. These results suggest the lack of a functional hasp gene in L. (V.) panamensis, suggesting probably the loss of the complete gene family in this species of the Viannia subgenus.

Key words: Leishmania, polymerase chain reaction; cloning, molecular; molecular sequence data, enzyme-linked immunosorbent assay; blotting, Western.

Los parásitos clasificados en el género Leishmania están agrupados en dos grandes subgéneros conocidos como Leishmania y Viannia. En el subgénero Leishmania se encuentran clasificadas todas las especies del Viejo Mundo y algunas del Nuevo Mundo en el complejo mexicana, mientras que el subgénero Viannia está restringido a especies del continente americano (1).

En Colombia se presentan casos por Leishmania sp. de ambos subgéneros; sin embargo, la mayoría de los aislamientos son de Leishmania (Viannia) panamensis, seguidos de Leishmania (Viannia) braziliensis, los cuales causan leishmaniasis cutánea y mucocutánea $(2,3)$, aunque existen pequeños focos de leishmaniasis cutánea ocasionados por Leishmania (Viannia) guyanensis y Leishmania (Leishmania) mexicana. La leishmaniasis visceral es causada casi exclusivamente por Leishmania (Leishmania) infantum chagasi.

Los subgéneros presentan diferencias genéticas, moleculares, bioquímicas y en la presentación clínica de la enfermedad que causan. Entre estas diferencias se han documentado las siguientes: 1) las especies de Leishmania del Viejo Mundo son transmitidas al hospedero vertebrado por insectos del género Phlebotomus, mientras que las del Nuevo Mundo, entre ellas las de subgénero Viannia, son transmitidas por insectos del género Lutzomyia (4);2) variaciones en el patrón y nivel

\author{
Correspondencia: \\ Marcel Marín, Calle 62 No. 52-59, SIU, laboratorio 632, \\ apartado aéreo 1226, Medellín, Colombia. \\ Teléfono: (574) 219 6507; fax (574) 2196511 \\ mvmarcel@gmail.com
}

Recibido: 25/02/08; aceptado:31/07/08 de expresión de algunas moléculas como gp63, gp46 (5-9) y el glucoconjugado de superficie LPG (10); 3) el mejor modelo animal para el estudio de las especies del subgénero Leishmania es el ratón; sin embargo, el hámster parece ser el más adecuado para las especies del subgénero Viannia $(11,12)$; 4) la comparación del genoma de $L$. (V.) braziliensis con el genoma de dos especies del subgénero Leishmania, Leishmania (Leishmania) major y $L$. (L.) infantum, reveló diferencias importantes en varios niveles: $L$. ( $L$.) major y $L$. (L.) infantum tienen 36 cromosomas mientras que $L$. $(V$.$) braziliensis tiene 35$, quizá como consecuencia de un evento de fusión entre los cromosomas 20 y $34(9,13)$; la presencia en $L$. (V.) braziliensis de genes involucrados en la maquinaria para ARN de interferencia que están ausentes en $L$. ( $L$.) major (14) y $L$. ( $L$.) infantum; la ausencia o inactivación de genes y proteínas caracterizados en las especies del Viejo Mundo a través de pseudogenes; asimismo, la comparación de los genomas secuenciados de estas tres especies han permitido encontrar cinco genes específicos para $L$. (L.) major, 26 para $L$. (L.) infantum y 47 en $L$. (V.) braziliensis (9).

Cuatro proteínas hidrofílicas de superficie (HASP) denominadas HASPA1, HASPA2, HASPB1 y HASPB2 de L. (L.) major, se relacionan estrechamente y se expresan exclusivamente en los promastigotes metacíclicos o infecciosos y en amastigotes (15-17). Estas proteínas son codificadas por dos genes diferentes, uno de 222 pb (haspa) y otro de $534 \mathrm{pb}$ (haspb), los cuales presentan secuencias idénticas en el extremo $5^{\prime}$ y 3 ' de sus marcos de lectura. La proteína HASPB contiene 5,5 repeticiones ricas en prolina, que comprenden el $45 \%$ del total de los aminoácidos. 
Cada repetición contiene 14 aminoácidos divididos en dos bloques repetitivos de siete aminoácidos: PKEDGHA y PKNDDHA (15).

La proteína HASPB se ha empleado como molécula blanco de pruebas diagnósticas en pacientes con leishmaniasis cutánea causada por $L$. (L.) major (18) y en leishmaniasis visceral por $L$. (L.) donovani (19). También se han realizado ensayos de inmunización con la proteína recombinante HASPB de L. (L.) donovanien el modelo de ratón y se ha podido demostrar que confiere protección contra leishmaniasis visceral (20).

Debido a las características que existen entre el patrón de expresión de las proteínas HASP con la capacidad infecciosa del parásito y su potencial uso en el desarrollo de pruebas diagnósticas y esquemas de inmunización, en la presente investigación se realizó la búsqueda de los genes ortólogos a hasp en cepas de L. (V.) panamensis.

\section{Materiales y métodos}

\section{Parásitos}

Se utilizó ADN purificado de promastigotes de las siguientes cepas: $L$. $(V$.) panamensis de referencia (MHOM/PA/71/LS94), L. (V.) panamensis colombianas (MHOM/CO/87/UA140), (MHOM/CO/ 94/UA806) y (MHOM/CO/87/UA936), L. (L.) major (MHOM/JL/80/Friedlin) y (MHOM/SU/73/5ASKH). Los parásitos se cultivaron en medio definido

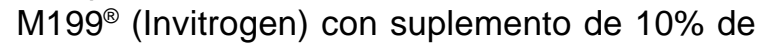
suero fetal bovino a $26{ }^{\circ} \mathrm{C}$ y se lavaron por centrifugación a $1.000 \mathrm{~g}$ por 10 minutos a $4^{\circ} \mathrm{C}$.

\section{Sueros}

Los sueros empleados en la presente investigación se obtuvieron de pacientes con leishmaniasis y ratones infectados con $L$. ( $V$.) panamensis, $L$. (L.) amazonensis o $L$. (L.) major. Los pacientes tenían el diagnóstico confirmado por examen directo, cultivo o reacción en cadena de la polimerasa (PCR) realizados en el Programa de Estudio y Control de Enfermedades Tropicales, PECET, de la Universidad de Antioquia, Colombia.

A todos los pacientes se les solicitó el consentimiento informado y las muestras se tomaron siguiendo las indicaciones institucionales para ese fin, así como lo expresado en la
Declaración de Helsinski. Para la obtención de los sueros de los ratones, se solicitó consentimiento informado al Comité de Ética de la Universidad de Antioquia para la experimentación con animales.

\section{Aislamiento y purificación de ADN}

El ADN se purificó a partir de $1 \times 10^{8}$ promastigotes empleando el método convencional de fenol: cloroformo (21). La cantidad y calidad del ADN genómico purificado se evaluó por espectrofotometría y electroforesis en agarosa al 1\% en TAE (40 mM Tris, $18 \mathrm{mM}$ ácido acético, $2 \mathrm{mM}$ EDTA pH 8,0 ) con $0,5 \mu \mathrm{g} / \mathrm{ml}$ bromuro de etidio.

\section{Purificación de ARN y síntesis de ADNC}

Se purificó ARN de promastigotes obtenidos de la fase logarítmica (día 3) y estacionaria (día 6) de la cepa de referencia $L$. $(V$.) panamensis (MHOM/PA/71/LS94) empleando las condiciones descritas en Trizo $^{\circledR}$ (Invitrogen). La transcripción reversa para la síntesis del ADN copia (ADNc) se hizo con un oligo-dt y la transcriptasa reversa $\mathrm{M}$ MuLV ${ }^{\circledR}$ (Fermentas) de acuerdo con las instrucciones del fabricante. La calidad del ADNc fue verificada por electroforesis en gel de agarosa al $1 \%$ teñido con $0,5 \mu \mathrm{g} / \mathrm{ml}$ bromuro de etidio (no se presenta el dato).

\section{Amplificación de los genes hasp}

Para la amplificación del marco de lectura de los genes hasp en las cepas de $L$. ( $V$.) panamensis y en $L$. ( $L$.) major, se empleó un par de cebadores diseñados con la secuencia reportada para el gen haspb de L. (L.) major (geneDB LmjF23.1060): GBP sentido (5' CGGGATCCATGGGAAGCTCTTGC ACG 3') y GBP antisentido (5' CCCAAGCTTCTAG TTGCCGGCAGCGTG 3'). Estos cebadores contienen las secuencias de restricción para las enzimas BamHI y HindIII, respectivamente. La PCR se realizó con los siguientes reactivos y concentraciones: $400 \mathrm{ng}$ de ADN o $1 \mu \mathrm{g}$ de ADNc, $0,5 \mathrm{mM}$ de cada cebador, $200 \mathrm{mM}$ dNTP, $2 \mathrm{mM}$ $\mathrm{MgCl}_{2}$, $1 \mathrm{X}$ del tampón de la enzima, $5 \mathrm{UI} / \mu \mathrm{l}$ Taq polimerasa y agua hasta un volumen final de reacción de $25 \mu$ l.

Las condiciones de amplificación empleadas fueron: un ciclo inicial de desnaturalización del 
ADN a $94^{\circ} \mathrm{C}$ por 7 minutos seguido de 30 ciclos desnaturalización del ADN a $94^{\circ} \mathrm{C}$ por 1 minuto, alineamiento de cebadores a $60^{\circ} \mathrm{C}$ por 1 minuto, polimerización a $72^{\circ} \mathrm{C}$ por 1 minuto y 1 ciclo final de extensión a $72^{\circ} \mathrm{C}$ por 7 minutos. El producto de la amplificación se visualizó en gel de agarosa al $1 \%$ teñido con $0,5 \mu \mathrm{g} / \mathrm{ml}$ de bromuro de etidio.

\section{Clonación y secuenciación}

Los productos amplificados por PCR fueron clonados en el vector pGEM-T-Easy ${ }^{\circledR}$ (Promega) siguiendo el protocolo del fabricante. La secuenciación de los productos se realizó en el University College of London en Inglaterra, empleando los cebadores que reconocen las secuencias de los promotores SP6 y T7 presentes en el vector de clonación.

\section{Análisis bioinformático}

Las secuencias obtenidas fueron analizadas con BLAST-n (Basic Local Aligment Search Toolnucleotide) para determinar si existía homología con las secuencias de los genes hasp reportadas en los bancos de genes de NCBI (http:// www.ncbi.nlm.nih.gov/blast/Blast.cgi) y geneDB (http://www.genedb.org/genedb/leish/).

\section{Expresión y purificación de proteínas recombinantes}

Los marcos de lectura de los genes haspa y haspb de $L$. (L.) major previamente clonados y secuenciados en el vector pGEM-T-Easy ${ }^{\circledR}$ (Promega), fueron subclonados en el plásmido de expresión pMAL (New England Biolab) usando las secuencias de restricción BamHI y Hind III.

Las células competentes Escherichia coli TB1 fueron transformadas con los plásmidos de PMAL que contenían los genes hasp de L. (L.) major, se sembraron en agar Luria-Bertani con $100 \mu \mathrm{g} / \mathrm{ml}$ de ampicilina (LB/Amp $100 \mu \mathrm{g} / \mathrm{ml}$ ) y se incubaron a $37^{\circ} \mathrm{C}$ durante 12 horas.

Una colonia de las bacterias TB1 trasformadas con el plásmido fue inoculada en $10 \mathrm{ml}$ de LB/ Amp $100 \mu \mathrm{g} / \mathrm{ml}$ y se incubó durante toda la noche a $37^{\circ} \mathrm{C}$ a $250 \mathrm{rpm}$.

Este cultivo inicial se empleó para inocular un litro de LB/Amp a $100 \mu \mathrm{g} / \mathrm{ml}$. Cuando el cultivo alcanzó una densidad óptica de 0,4-0,6 a $600 \mathrm{~nm}$, se adicionó $1 \mathrm{mM}$ de isopropil- $\beta$-D-tio-galactósido (IPTG) para inducir la expresión de la proteína recombinante y se incubó 4 horas adicionales bajo las mismas condiciones.

El litro de cultivo bacteriano se centrifugó a $4.000 \mathrm{~g}$ durante $15 \mathrm{~min}$ a $4{ }^{\circ} \mathrm{C}$. Las dos proteínas recombinantes rHASPB y rHASPA fueron purificadas en una columna de amilosa siguiendo las recomendaciones del fabricante (New England Biolab).

\section{Detección de anticuerpos contra la proteína HASP}

Para detectar anticuerpos específicos contra las proteínas HASP mediante un ensayo FAST $^{{ }_{-}}$ ELISA (Falcon Assay Screening Test-EnzymeLinked ImmunoSorbent Assay) se emplearon diferentes tipos de sueros de pacientes con leishmaniasis: ocho de leishmaniasis visceral, ocho de leishmaniasis cutánea y seis de leishmaniasis mucocutánea. Los sueros control se obtuvieron de tres individuos con prueba de Montenegro negativa (M-) y tres individuos con Montenegro positiva $(\mathrm{M}+)$.

En una placa para $\mathrm{FAST}^{\circledR}$-ELISA durante toda la noche a $4{ }^{\circ} \mathrm{C}$ se fijaron $100 \mu \mathrm{g} / \mathrm{ml}$ del péptido sintético correspondiente a la unidad repetitiva de la proteína HASPB1 de $L$. (L.) donovani (MHOM/ $\mathrm{ET} / 67 / \mathrm{L28}$ ) (19) diluido en PBS pH 7,6. Al día siguiente se lavaron los pozos con PBS para retirar el exceso de péptido y se bloquearon con $1 \%$ de albúmina sérica bovina en PBS pH 7,2 que contenía $0,5 \mathrm{M}$ de $\mathrm{NaCl}$ y $0,1 \%$ de tritón X-100.

En cada pozo se adicionaron $200 \mu$ de los sueros de los pacientes, diluidos 1:100 en la solución tampón de bloqueo y la placa se incubó por 2 horas a temperatura ambiente. Posteriormente, se realizaron cinco lavados con PBS-Tween $0,1 \%$ y se incubó con el anticuerpo secundario anti-lgG humano conjugado con peroxidasa ${ }^{\circledR}$ (Bio-Rad) diluido 1:2000 durante 2 horas en la misma solución. La reacción de FAST $^{\circledR}$-ELISA se reveló con $100 \mu \mathrm{l}$ de una solución de ortofenildiamina ${ }^{\circledR}$ (Sigma) como sustrato. La reacción fue leída con un lector de ELISA (Bio-Rad) a una longitud de onda de $490 \mathrm{~nm}$. 
Las pruebas de Western blot se realizaron con las dos isoformas proteicas recombinantes HASP de $L$. (L.) major (rHASPB y rHASPA) fusionadas a la proteína MBP (Maltose Binding Protein). Ambas proteínas se separaron por electroforesis en gel de poliacrilamida SDS-PAGE al $12 \%$ y se transfirieron a membranas de nitrocelulosa, las cuales fueron bloqueadas toda la noche con $5 \%$ de leche descremada en TBS-Tween $0,1 \% \mathrm{pH}$ 7,6 . Posteriormente, las membranas se cortaron en tirillas de $0,5 \mathrm{~cm}$ y cada tirilla se incubó con diferentes sueros diluidos 1:100 en TBS-Tween $0,1 \% \mathrm{pH} \mathrm{7,6.}$

Los sueros empleados para las Western blot fueron: tres sueros de pacientes con leishmaniasis visceral, tres sueros de pacientes con leishmaniasis cutánea y un suero de un paciente con leishmaniasis cutánea difusa causada por $L$. ( $L$.) amazonensis. También se usaron sueros de ratones BALB/c, infectados con $L$. (V.) panamensis, L. (L.) amazonensis y L. (L.) major.

Como anticuerpos secundarios se emplearon anticuerpos anti-IgG humano y anti-ratón conjugados con peroxidasa y diluidos 1:2000 también en TBS-Tween 0,1\% pH 7,6. Las tirillas se revelaron con quimioluminiscencia (SuperSigna $^{\circledR}$ Pierce) y la señal de luz generada fue captada con el sistema Chemi-Doc $\mathrm{XRS}^{\circledR}$ (BioRad).

\section{Resultados}

Presencia del pseudogen haspa en L. (V.) panamensis

En $L$. (L.) major se amplificaron los dos productos de PCR, uno de 534 pb y otro de 222 pb, ambos del tamaño esperado según lo reportado en la literatura (15), aunque el fragmento de $222 \mathrm{pb}$ amplificó con mayor eficiencia.

En las cepas de L. (V.) panamensis (MHOM/PA/ 71/LS94), (MHOM/CO/87/UA140), (MHOM/CO/ 94/UA806) y (MHOM/CO/87/UA936, se amplificó un fragmento de $400 \mathrm{pb}$ y otro de $850 \mathrm{pb}$ (figura 1).

El análisis de las secuencias de 534 y 222 pb amplificadas en $L$. ( $L$.) major presentó un $100 \%$ de identidad con la reportadas en geneDB. Por el contrario, las secuencias obtenidas de los

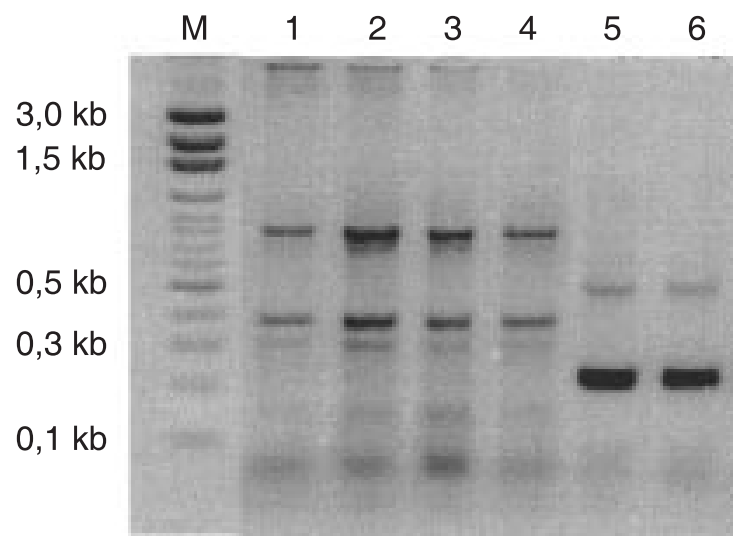

Figura 1. Amplificación del gen haspb a partir de ADN de $L$. (V.) panamensis. Se observa un producto de $400 \mathrm{pb}$ y otro de $850 \mathrm{pb}$ en las cepas de $L$. (V.) panamensis; las cepas control de $L$. (L.) major amplificaron en el tamaño esperado ( 534 y 222 pb). Carril 1: L. (V.) panamensis (MHOM/PA/71/ LS94); carril 2: L. (V.) panamensis (MHOM/CO/87/UA140), carril 3: L. (V.) panamensis (MHOM/CO/94/UA806); carril 4: L. (V.) panamensis (MHOM/CO/87/UA936); carril 5: L. (L.) major (MHOM/JL/80/Friedlin); carril 6: L. (L.) major (MHOM/ SU/73/5ASKH); carril M: Marcador de peso molecular.

amplificados de $L$. (V.) panamensis no presentaron identidad significativa con ninguna de las secuencias de hasp reportadas, ni mostraron las repeticiones características de este gen observadas en $L$. (L.) major (no se muestran los datos).

No hubo amplificación a partir del ADNc obtenido en la fase logarítmica (día 3) de la cepa de referencia (MHOM/PA/71/LS94) de $L$. (V.) panamensis; sin embargo, con el ADNc de la fase estacionaria (día 6) se logró amplificar y secuenciar un fragmento de $450 \mathrm{pb}$ que tuvo una identidad del $60 \%$ en relación con la secuencia del gen haspa de $222 \mathrm{pb}$ de L. (L.) major (LmjF23.1088) (figura 2a). Cuando se analizó la secuencia de $450 \mathrm{pb}$ con un programa traductor de secuencias de nucleótidos a aminoácidos (http://www. ncbi. nlm.nih.gov/projects/gorf/), se encontró un marco de lectura en los primeros $300 \mathrm{pb}$ que contiene una serie de 6 bloques repetitivos conformados por nueve aminoácidos (GARCRQLEA). En el primer bloque hay una sustitución en los dos primeros aminoácidos, glicina $(\mathrm{G})$ y alanina $(\mathrm{A})$, por ácido glutámico $(E)$ y prolina $(P)$. Además, en el tercer bloque, el primer aminoácido $G$ fue sustituido por E. Es llamativo que cada bloque está seguido de 
A

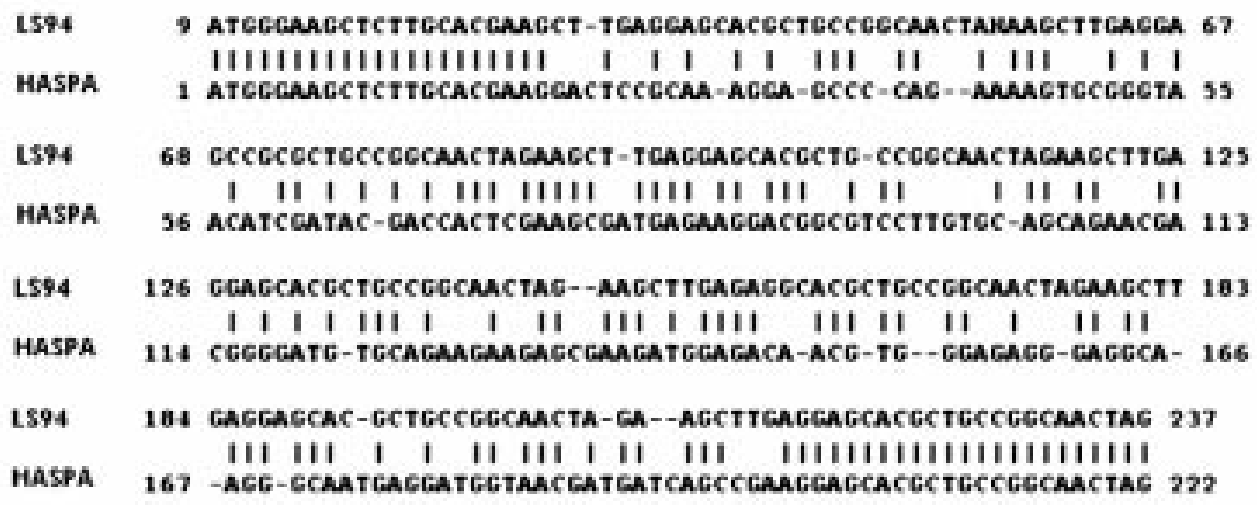

B

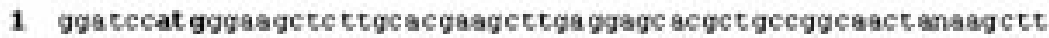

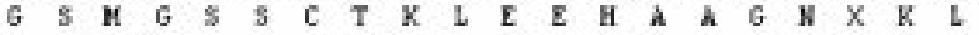

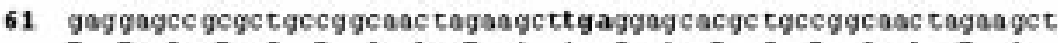

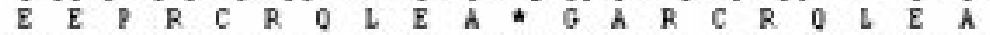
121 tya ggogcacgct gecggcasc tagaagcttgagoggcacge tgccggcasc tagas get - g a R C R 0 l E a * E h R C R 0 l E 181 tga ggage acgct gecggcaac tagaagcttgaggagcacge tgceggcasc tagaa gct - c a r c r 0 l e a * c a R c R 0 L e a 241 tgagageacgetgecgucaset ayastgagagcacgetgeeggeasetaga ageteg * E H A A G N *

Figura 2. Secuencia del pseudogen haspa de L. (V.) panamensis (MHOM/PA/71/LS94). (A) La secuencia de nucleótidos de $450 \mathrm{pb}$ muestra una identidad del $60 \%$ en relación con la secuencia haspa de L. (L.) major (LmjF23.1088). (B) Secuencia de aminoácidos deducida a partir de la secuencia de nucleótidos presentada en el panel A. Los asteriscos en la secuencia corresponden a codones de parada localizados después de cada bloque repetitivo de nonapéptidos.

un codón de parada, lo cual podría indicar que esta secuencia corresponde a un pseudogen (figura 2b). La estructura de la secuencia de 450 $\mathrm{pb}$ de $L$. (V.) panamensis es semejante a lo reportado para esta familia de genes en $L$. (L.) major, L. (L.) chagasi y L. (L.) donovani, donde la proteína HASPB contiene bloques repetitivos de aminoácidos $(15,22,23)$.

\section{Detección de anticuerpos específicos para la proteína HASP en suero de pacientes con leishmaniasis}

Los resultados de la $\mathrm{FAST}^{\circledR}{ }^{\circledR}$ ELISA demuestran la presencia de anticuerpos específicos contra el péptido sintético de la unidad repetitiva de la proteína HASPB1 de $L$. (L.) donovani en sueros de pacientes con leishmaniasis visceral con títulos por encima del punto de corte, el cual corresponde a 0,027 de densidad óptica. Por el contrario, los sueros de pacientes con leishmaniasis cutánea, mucocutánea, con prueba de Montenegro positiva y negativa no presentaron títulos de anticuerpos contra el péptido sintético por encima del punto de corte (figura 3).

También se determinó la presencia de anticuerpos contra las proteínas recombinantes rHASPA (58,3 $\mathrm{kDa})$ y rHASPB $(70,4 \mathrm{kDa})$ en sueros de pacientes con leishmaniasis mediante la Western blot. Los sueros de pacientes con leishmaniasis visceral presentaron anticuerpos específicos contra las dos proteínas recombinantes, con excepción del suero del primer paciente, el cual sólo presentó anticuerpos para la proteína rHASPB (figura 4, carriles 1-3). No se encontraron anticuerpos que reconocieran epítopos en ambas proteínas recombinantes en los sueros de los pacientes con leishmaniasis cutánea causada por L. (V.) panamensis (figura 4, carriles 4-6), ni en el suero 


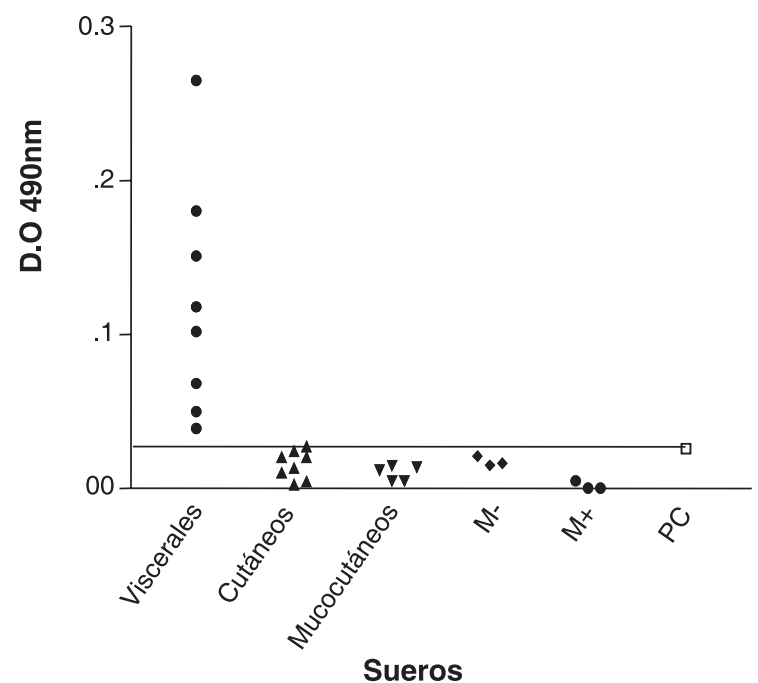

Figura 3. $\mathrm{FAST}^{\circledR}{ }_{-}$-ELISA empleando el péptido sintético del bloque repetido de HASPB1 de $L$. (L.) donovani (MHOM/ET/ 67/L28). Se detectaron títulos de anticuerpos por encima del punto de corte en sueros de individuos con leishmaniasis visceral. Se emplearon los siguientes sueros: 8 de pacientes con leishmaniasis visceral, 8 de pacientes con leishmaniasis cutánea y 6 de pacientes con leishmaniasis mucocutánea, 3 de pacientes Montenegro negativo (M-) y 3 de pacientes Montenegro positivos $(\mathrm{M}+)$. El punto de corte $(\mathrm{PC})$ establecido para la prueba fue de 0,027 de densidad óptica (DO).

de un paciente con leishmaniasis difusa causada por $L$. (L.) amazonensis (figura 4, carril 7). Un suero de un ratón $B A L B / c$ infectado con $L$. (L.) major, considerado como control positivo, presentó anticuerpos que reconocieron la proteína rHASPB y con menor intensidad la proteína rHASPA (figura 4 , carril 9). Similar a los resultados obtenidos con los sueros de los pacientes, no se detectaron anticuerpos en los sueros de los ratones BALB/C infectados con una cepa de $L$. ( $V$.) panamensis o L. (L.) amazonensis (figura 4, carriles 8 y 10 ).

\section{Discusión}

Los resultados experimentales de la presente investigación sugieren la pérdida de los genes que codifican para la familia de las proteínas HASP en $L$. $(V$.) panamensis, lo que ratifica las divergencias entre las especies de Leishmania del Nuevo y el Viejo Mundo, dadas las características de las secuencias encontradas y el polimorfismo en el tamaño de las moléculas de ADN amplificadas por PCR con los cebadores diseñados para el gen haspb de L. (L.) major. Además, mediante Southern blot empleando una sonda heteróloga del gen haspb de L. (L.) major, no se detectó la presencia de este gen en el genoma de $L$. ( $V$.) panamensis y $L$. ( $V$.) braziliensis (no se presentan los datos).

En el análisis de identidad de secuencias obtenidas en el presente estudio empleando Blast$\mathrm{n}$ contra el genoma de $L$. (V.) brazilensis (http:// www.genedb.org/genedb/lbraziliensis/), tampoco se evidenció la presencia de genes ortólogos de hasp en esta especie del Nuevo Mundo, lo cual fue confirmado recientemente mediante un análisis comparativo del genoma de las tres especies actualmente secuenciadas, $L$. (L.) major, $L$. (L.) infantum y $L$. $(V$.) brazilensis, donde se encontró la ausencia del locus que codifica para estas proteínas en $L$. ( $V$.) braziliensis (9).

No obstante, en $L$. (L.) amazonensis la secuencia homóloga al gen haspb fue amplificada por PCR e identificada mediante Southern blot y obtención de la secuencia, con una identidad del $95 \%$ en relación con la secuencia de aminoácidos de la proteína HASPB de L. (L.) major (no se presentan los datos). Lo anterior indica que este gen se encuentra conservado en las especies pertenecientes al complejo mexicano como L. (L.) mexicana (genBank CAB64450) y L. (L.) amazonensis, las cuales pertenecen al subgénero Leishmania (24), en los cuales se identificaron y caracterizaron inicialmente los genes de la familia de proteínas HASP. El análisis detallado de la expresión de otros genes, como gp46 y HSP70, ha permitido establecer una mayor relación de $L$. ( $L$.) amazonensis con las especies de Leishmania del Viejo Mundo $(6,25)$.

Cuando se realizó la amplificación de los genes hasp usando ADN genómico de L.(V.) panamensis, se observaron varios amplificados (figura 1, carril 1-4), de los cuales sólo se secuenciaron los productos más representativos alrededor de 400 pb y $850 \mathrm{pb}$. Las secuencias obtenidas no presentaron identidad significativa con los genes hasp de $L$. (L.) major, como se mencionó en los resultados. Otros productos amplificados a partir del ADN genómico generaron una señal bastante débil, debido quizá a las pocas copias amplificadas o a que se trata de productos amplificados inespecíficos. 


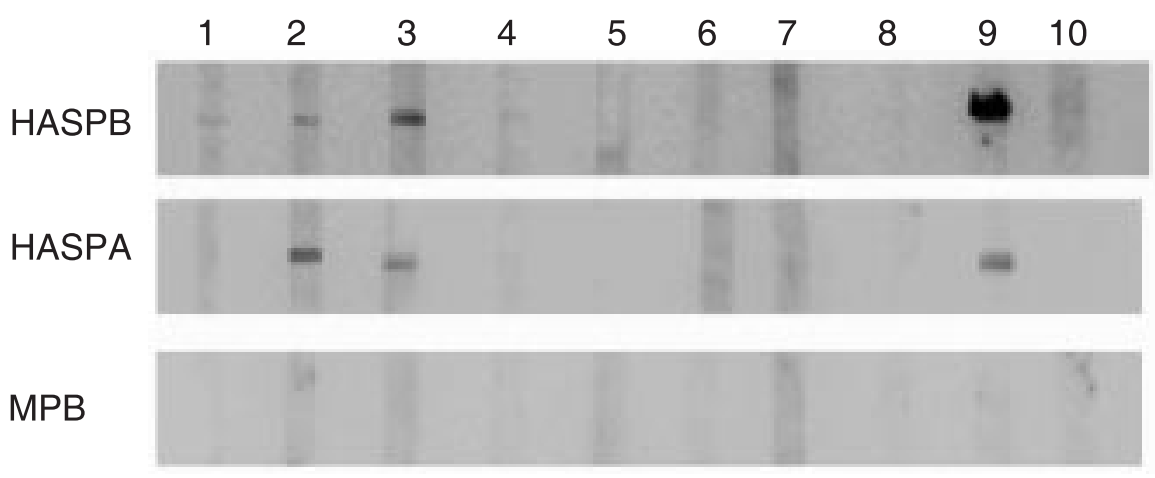

Figura 4. Western blot con las proteínas recombinantes HASPA, HASPB de L. (L.) major y la proteína de unión a maltosa (MBP), empleada como proteína de fusión en el proceso de purificación de HASPA y HASPB. Los sueros fueron empleados a una dilución de 1:50. La distribución de las muestras fueron: carriles 1-3: sueros de pacientes con leishmaniasis visceral; carriles 4-6: sueros de pacientes con leishmaniasis cutánea por L. (V.) panamensis; carril 7: suero de paciente con leishmaniasis difusa causada por $L$. (L.) amazonensis; carril 8: suero de ratón BALB/c infectado con $L$. ( $V$.) panamensis; carril 9: suero de ratones BALB/c infectados con $L$. (L.) major; carril 10: suero de ratones BALB/c infectados con $L$. ( $L$.) amazonensis.

Para estar seguros de la existencia de algún gen ortológo en $L$. $(V$.) panamensis, se realizó una PCR empleando ADNc de $L$. (V.) panamensis con el fin de amplificar una posible secuencia transcrita a ARNm. La obtención de un producto de $450 \mathrm{pb}$ a partir de ADNc de $L$. (V.) panamensis del día 6 de crecimiento, el cual presenta una identidad del $60 \%$ con el gen haspa de $L$. (L.) major, evidencia su transcripción en el estadio infeccioso de $L$. ( $V$.) panamensis. Sin embargo, la presencia de varios codones de parada en la secuencia de $450 \mathrm{pb}$ sugiere que, posiblemente, este gen fue sometido a una presión selectiva fuerte que generó modificaciones genéticas que lo llevaron a convertirse en un pseudogen en $L$. (V.) panamensis $y$, probablemente, en otras especies del subgénero Viannia.

Hoy en día se sabe, por la obtención de la secuencia de tres especies de Leishmania, que el genoma de $L$. ( $V$.) braziliensis es el que presenta el mayor número de pseudogenes comparado con $L$. (L.) major y $L$. (L.) infantum (161 en $L$. ( $V$.$) braziliensis versus 97$ en $L$. (L.) major y sólo 41 en $L$. (L.) infantum) (26), entre ellos hasp. Estos hallazgos muestran claramente que las especies del subgénero Viannia han sufrido procesos de pérdida o silenciamiento de varios genes en su genoma, como en el caso de los genes gp46, Mat-1, SHERPy PFPI $(6,8,9,27)$.
La ausencia de anticuerpos contra las proteínas HASP en los sueros de pacientes con leishmaniasis cutánea, apoya las evidencias que señalan la falta de los genes hasp funcionales en la especie de L. (V.) panamensis. Por el contrario, sólo los sueros obtenidos de pacientes con leishmaniasis visceral mostraron presencia de anticuerpos específicos contra el péptido de la unidad repetitiva de la proteína HASPB1 de L. donovani $y$, en menor proporción, contra las proteínas recombinantes rHASPA y rHASPB de $L$. major (no se presentan los resultados de ELISA).

Este hallazgo es de esperarse dado que la especie causante de leishmaniasis visceral en Colombia, L. (L.) infantum chagasi, es una especie perteneciente al subgénero Leishmania (22). Sin embargo, un suero de un paciente con leishmaniasis difusa infectado con $L$. (L.) amazonensis y una mezcla de sueros de seis ratones $B A L B / c$ infectados con $L$. (L.) amazonensis no presentaron anticuerpos que reconocieran las proteínas recombinantes HASP de L. (L.) major, lo cual es un resultado inesperado dada la existencia de un gen haspb ortólogo en $L$. (L.) amazonensis.

Un Western blot con lisados obtenidos de $L$. (L.) amazonensis y un suero policlonal desarrollado contra la proteína recombinante HASPB de $L$. ( $L$.) major, no detectó la expresión de la proteína nativa HASPB en promastigotes estacionarios ni en 
amastigotes de L. (L.) amazonensis (no se presentan los datos), lo cual pudo deberse a que estas proteínas sufren modificaciones posteriores a la traducción, como $\mathrm{N}$-miristilación y palmitoilación (28); además, en Leishmania pueden existir mecanismos desconocidos que regulan la traducción de proteínas.

Recientemente fue publicado un caso similar al reportado en el presente estudio con el gen que codifica la proteasa I de Pirococcus furiosus-like (PFPl) de L. (L.) mexicana, en el cual, a pesar de existir el gen completo y de encontrarse el ARNm poliadenilado, no fue posible detectar la proteína en el parásito. Además, es interesante que en $L$. $(V$.) braziliensis se encontró un pseudogen para PFPI (27).

Funcionalmente, se considera que las proteínas de la familia HASP podrían estar involucradas en la transmisión del promastigote metacíclico a través del vector flebótomo, mientras que en el estadio de amastigote, la expresión de las proteínas HASP podría tener un papel en la supervivencia del parásito dentro del macrófago. Sin embargo, los experimentos realizados por McKean et al., usando una línea de $L$. (L.) major con una deleción homóloga del locus LmcDNA16, mostraron que estos parásitos son igual de virulentos a los silvestres en la invasión a los macrófagos y supervivencia intracelular, tanto in vitro como in vivo (29). Si L. (V.) panamensis y las demás especies del subgénero Viannia naturalmente carecen del locus LmcDNA16, tal vez podrían presentar una diferencia en la respuesta inmune generada en el huésped mamífero en comparación con $L$. (L.) major, pero esta hipótesis tendría que ser comprobada.

Por otro lado, los experimentos de inmunización con la proteína recombinante HASPB1 de $L$. (L.) donovanien ratones $B A L B / c$ confirieron protección contra la leishmaniasis visceral inducida experimentalmente, lo cual la postula como posible candidata a una vacuna para leishmaniasis visceral (20), pero hay que tener en cuenta que esta proteína parece presentar una elevada presión selectiva en la naturaleza que podría explicar la heterogeneidad interespecífica en el número de repeticiones de aminoácidos dentro de la proteína HASPB en cepas silvestres de $L$. ( $L$.) major (23) y $L$. (L.) donovani (30) y la posible pérdida o silenciamiento de esta familia de genes en las especies pertenecientes al subgénero Viannia.

En conclusión, los resultados presentados en esta investigación sugieren la ausencia de la familia de proteínas hidrofílicas de superficie en $L$. ( $V$.) panamensis, lo que aumenta las evidencias experimentales que señalan el grado de divergencia evolutiva que existe entre las especies del subgénero Viannia y las especies del subgénero Leishmania.

\section{Conflicto de intereses}

Los autores manifiestan que no existe ningún conflicto de intereses.

\section{Financiación}

Esta investigación fue financiada con fondos del CODI, Universidad de Antioquia CPT-0104 y de la Fundación para la promoción de la investigación y la tecnología, Banco de la República, Proyecto № 1397.

\section{Referencias}

1. Killick-Kendrick R. Biology of leishmania in phlebotomine sand flies. In: Lumsden WH, Evans DA, editors. Biology of the kinetoplastida. London: Academic Press; 1979. p. 395-460.

2. Vélez ID, Hendrick E, Robledo SM, Agudelo SP. Leishmaniosis cutánea en Colombia y género. Cad Saúde Pública. 2001;17:171-80.

3. Ovalle CE, Porras L, Rey M, Ríos M, Camargo YC. Distribución geográfica de especies de Leishmania aisladas de pacientes consultantes al Instituto Nacional de Dermatología Federico Lleras Acosta, E.S.E., 19952005. Biomédica. 2006;26(Supl.1):145-51.

4. Lane RP. Sandflies (Phlebotominae). In: Lane RP, Crosskey RW, editors. Medical insects and arachnids. Cambridge: Chapman and Hall; 1993. p. 78-119.

5. Kedzierski L, Montgomery J, Bullen D, Curtis J, Gardiner E, Jimenez-Ruiz A, et al. A leucine-rich repeat motif of Leishmania parasite surface antigen 2 "binds to macrophages through the complement receptor 3. J Immunol. 2004;172:4902-6.

6. McMahon-Pratt D, Traub-Cseko Y, Lohman KL, Rogers DD, Beverley SM. Loss of the GP46/M-2 surface membrane glycoprotein gene family in the Leishmania braziliensis complex. Mol Biochem Parasitol. 1992;50:151-60. 
7. McMahon-Pratt D, Alexander J. Does the Leishmania major paradigm of pathogenesis and protection hold for New World cutaneous leishmaniases or the visceral disease?. Immunol Rev. 2004;201:206-24.

8. Marín M, Muskus C, Ramírez JR, Arbeláez LF, Alzate JF, Berberich C. The gene encoding the metacyclogenesis-associated transcript Mat-1 is conserved in the genus Leishmania and shows a tendency to form dimers upon protein expression. Parasitol Res. 2000;86:431-5.

9. Peacock CS, Seeger K, Harris D, Murphy L, Ruiz JC, Quail MA, et al. Comparative genomic analysis of three Leishmania species that cause diverse human disease. Nat Genet. 2007;39:839-47.

10. Muskus, C, Segura I, Oddone R, Turco SJ, Leiby DA, Toro L, et al. Carbohydrate and LPG expression in Leishmania Viannia subgenus. J Parasitol. 1997;83: 671-8.

11. Hommel M, Jaffe CL, Travi B, Milon G. Experimental models for leishmaniasis and for testing anti-leishmanial vaccines. Ann Trop Med Parasitol. 1995;89(Suppl.1):55-73.

12. Henao HH, Osorio Y, Saravia NG, Gómez A, Travi B. Eficacia y toxicidad de los antimoniales pentavalentes (Glucantime $\AA^{\circledR}$ y Pentostam ${ }^{\circledR}$ ) en un modelo animal de leishmaniasis cutánea americana: aplicación de la luminometría. Biomédica. 2004;24:393-402.

13. Britto C, Ravel C, Bastien P, Blaineau C, Pages M, Dedet JP, et al. Conserved linkage groups associated with large-scale chromosomal rearrangements between Old World and New World Leishmania genomes. Gene. 1998;222:107-17.

14. Robinson KA, Beverley SM. Improvements in transfection efficiency and tests of RNA interference (RNAi) approaches in the protozoan parasite Leishmania. Mol Biochem Parasitol. 2003;128:217-28.

15. Flinn HM, Rangarajan D, Smith DF. Expression of hydrophilic surface protein in infective stages of Leishmania major. Mol Biochem Parasitol. 1994;65:259-70.

16. Pimenta PF, Pinto da Silva P, Rangarajan D, Smith DF, Sacks DL. Leishmania major: association of the differentially expressed gene B protein and the surface lipophosphoglycan as revealed by membrane capping. Exp Parasitol. 1994;79:468-79.

17. Rangarajan D, Gokool S, McCrossan MV, Smith DF. The gene B protein localise to the surface of Leishmania major parasites in the absence of metacyclic stage lipophosphoglycan. J Cell Sci. 1995; 108:3359-66.

18. Jensen AT, Gaafar A, Ismail A, Christensen CB, Kemp M, Hassan AM, et al. Serodiagnosis of cutaneous leishmaniasis: assessment of an enzyme- linked immunosorbent assay using a peptide sequence from gene B protein. Am J Trop Med Hyg. 1996;55:490-5.

19. Jensen AT, Gasim S, Moller T, Ismail A, Gaafar A, Kemp M, et al. Serodiagnosis of Leishmania donovani infections: assessment of enzyme-linked immunosorbent assays using recombinant $L$. donovani gene $B$ protein (GBP) and a peptide sequence of $L$. donovani GBP. Trans R Soc Trop Med Hyg. 1999;93:157-60.

20. Stager S, Smith DF, Kaye PM. Immunization with a recombinant stage-regulated surface protein from Leishmania donovani induces protection against visceral leishmaniasis. J Immunol. 2000;165:7064-71.

21. Medina-Acosta E, Cross G. Rapid isolation of DNA from trypanonosomatid protozoa using a simple "miniprep" procedure. Mol Biochem Parasitol. 1993;59:327-9.

22. Bhatia A, Daifalla NS, Jen S, Badaro R, Reed SG, Skeiky YA. Cloning, characterization and serological evaluation of K9 and K26: two related hydrophilic antigens of Leishmania chagasi. Mol Biochem Parasitol. 1999;102:249-61.

23. Alce TM, Gokool S, McGhie D, Stager S, Smith DF. Expression of hydrophilic surface proteins in infective stages of Leishmania donovani. Mol Biochem Parasitol. 1999;102:191-6

24. Lainson R, Shaw JJ. Evolution, classification and geographical distribution. In: Peters W, Killick-Kendrick $\mathrm{R}$, editors. The leishmaniases in biology and medicine. London: Academic Press; 1987. p. 1-120.

25. Folgueira C, Canavate C, Chicharro C, Requena JM. Genomic organization and expression of the HSP70 locus in New and Old World Leishmania species. Parasitology. 2007;134:369-77.

26. Smith DF, Peacock CS, Cruz AK. Comparative genomics: from genotype to disease phenotype in the leishmaniases. Int J Parasitol. 2007;37:1173-86.

27. Eschenlauer SC, Coombs GH, Mottram JC. PFPIlike genes are expressed in Leishmania major but are pseudogenes in other Leishmania species. FEMS Microbiol Lett. 2006;260:47-54.

28. Denny PW, Gokool S, Russell D, Field M, Smith D. Acylation-dependent protein export in Leishmania. J Biol Chem. 2000;275:11017-25.

29. McKean PG, Denny PW, Knuepfer E, Keen JK, Smith DF. Phenotypic changes associated with deletion and overexpression of a stage-regulated gene family in Leishmania. Cell Microbiol. 2001;3:511-23.

30. McKean PG, Trenholme KR, Rangarajan D, Keen J, Smith DF. Diversity in repeat-containing surface proteins of Leishmania major. Mol Biochem Parasitol. 1997;86:225-35. 